Int. J. Sudan Research, Vol. 7, No. 1, 2017

\title{
THE SIGNIFICANCE OF
}

\section{NUTRITIONAND DIETETIC}

\section{SERVICES IN MANAGING}

\section{CHRONIC KIDNEY DISEASE (CKD)}

\section{Nahlaa A. Khalifa}

Clinical Nutrition Department

Faculty of Applied Medical Sciences

King Abdulaziz University

P.O Box: 54539 Jeddah 21524, Saudi Arabia

Email: nahlaakhalifa@outlook.com/nkhalefa@kau.edu.sa 


\section{ABSTRACT}

Aim: (1) To evaluate the quality of nutrition and dietetics services delivered in the context of chronic kidney disease (CKD) to patients in Jeddah City. (2) To assess the involvement of Saudi emigrant dietitians in the renal setting

Methods: A descriptive, cross-sectional study with structured questionnaires for CKD units' administrators and emigrant Saudi dietitian alumni was used.

Results: Results showed that 7 (58.3\%) followed "National standards", 3 (25\%) followed "International standards", 1 (8.35\%) acknowledged following "both", and 1 (8.35\%) followed "Others". Of the total departments, all of which were private departments, 5 (41.7\%) were "Not accredited at all", 7 (58.3\%) departments, including the two governmental departments and another five private, were "Nationally accredited", and only $3(25 \%)$ departments, including the one governmental department and another two private departments, were "Internationally accredited". Only 4 (33.35\%) departments had only "one dietician", 2 (16.65\%) had "two dieticians", 2 (16.65\%) had "three dieticians", and 4 (33.35\%) had "more than three dieticians. None of the emigrant Saudi dietitians $(n=38)$ were involved with renal-related services.

Conclusions: CKD is considered as one of the main health problems globally and nationally. The important of dietitians and the dietetic services provided with CKD is well acknowledged in management of the disease. Nutrition services must be aware of all information of dietitians working in the facility in order to have beneficial results.

Practical implications: Further studies are needed in different areas to evaluate dietetic services in the context of CKD and diaspora of Saudi dietitians, and neighbours should be engaged in order to unify the services and ensure the importance of dietetics in renal settings.

Originality/value: This is the first in-depth study evaluating nutrition and dietetics services delivered to CKD patients in renal units in Jeddah city, and the first data about the Saudi emergent dietitians practice areas.

Key words: Chronic, Kidney, Disease, CKD, Dietetic, Services, Diaspora, Saudi

Reference to this paper should be made as follows: Khalifa, N. A. (2017) 'The significance of nutrition and dietetic services in managing Chronic Kidney Disease (CKD)', Int. J. of Sudan Research, Vol. 7, No. 1, pp.45-56.

\section{INTRODUCTION AND LITERATURE REVIEW}

\section{Chronic Kidney Disease}

Chronic kidney disease (CKD) is considered as one of the main health problems, nationally and globally. It is defined as a disorder that disturbs kidneys and lowers their ability to maintain health. CKD gradually disturbs renal functions that, if untreated and managed properly, can eventually lead to end stage renal disease (Escott-Stump, 2008).

\section{Stages of Chronic Kidney Disease}

Chronic kidney disease has five stages, classified according to the qualitative description kidney damage and glomerular filtration rate (GFR) and renal function. In stage one there is kidney damage and normal GFR, stage two has kidney damage and mild GFR, stage three is characterized by moderate GFR, stage four has severe GFR, and stage five is an end stage (Escott-Stump, 2008).

\section{Prevalence of CKD in Saudi Arabia}

Chronic kidney disease is an extensive prevalent public health subject. Globally the prevalence is estimated to be 8-16\% (Jha et al., 2013). 
With concerns about the incidence and prevalence of CKD and End Stage Renal Disease (ESRD) in Saudi Arabia, there are apparent trends in risk factors, etiology and demographics of patients with CKD.

A pilot study conducted by Alsuwaida et al. (2010) showed that the prevalence of CKD in Saudi Arabia was 5.7\%.

An epidemiological study from the activities of the World Kidney Day launched under the Theme, "Kidney Health for All", in 2015, showed the number of kidney patients in the Kingdom of Saudi Arabia (SA), based on the annual statistics of the Saudi Centre for Organ Transplantation, exceeds 17,000 , including 15,600 patients undertaking haemodialysis, while the number of those undertaking peritoneal dialysis totals 1,500: this number is in addition to the patients who are non-Saudis.

Another study conducted by Al-Sayyari and Shaheen (2011), showed that 10,230 patients in Saudi Arabia were on haemodialysis, while only $8.7 \%$ of the total of all patients undertaking dialysis were on peritoneal dialysis. However, the mortality rate among those was fortunately similar for haemodialysis patients.

\section{Healthcare Team for CKD Patient}

Good health care is continuously a team effort, particularly for people with CKD, as every member of the health care team provides special care for CKD patients. According to life Mkmpm, Partnering Your Healthcare Team 2015, the CKD health care team will probably include the following:

- General practitioner: first point of contact for help in managing chronic conditions;

- Renal coordinator: coordinates appointments with other healthcare teams;

- Medical social worker: provides emotional support and help in managing finances toward dialysis;

- The nephrologist: is a specialist in the renal field and has the most important role for the CKD patient;

- The pharmacist: helps in guiding in the way to take prescribed medications;

- The dietitian: helps in guiding towards making the right food choices to delay the progression of the disease.

A study conducted by Van Wamelen (1980), clarified the members of the medical team profession, the abilities and positions of a clinical dietitian as a member of the medical team, and emphasized the importance of good communication between doctors and dietitians for full utilization of the services of the hospital dietitian, as well as dietitians in private practice.

Additionally, the International Journal of Science and Research published a study undertaken by Idris and Al Jannakl (2013) that identified and evaluated King Khalid hospital's role of dietitians in its nutrition service. It set recommendations related to nutrition by using questionnaires to gather information concerning the role of dietitians from King Khalid hospital. The study concluded that there were not enough dietitians to manage illnesses that are related to nutrition. 


\section{Regulations and Standards in Renal Units}

A council of health services in 2006 implemented evidence-based clinical guidelines related to the dietetic management of adult patients with CKD. This was developed by summarizing the nutritional sections of the following published guidelines:

- Caring for Australians with Renal Impairment (CARI) Guidelines;

- Kidney Disease Outcomes Quality Initiative (K/DOQI) Clinical Practice Guidelines;

- American Dietetic Association (ADA) Medical Nutrition Therapy Evidence-Based Guides for Practice: Chronic Kidney Disease (non-dialysis) Medical Nutrition Therapy Protocol;

- ADA Guidelines for Nutritional Care of Renal Patients (3rd edition);

- European Dialysis and Transplant Nurses Association and European Renal Care Association (EDTNA/ERCA);

- Guidelines for the Nutritional Care of Adult Renal Patients (Ash et al., 2006).

A study from the American Dietetic Association and the National Kidney Foundation, conducted by Brommage et al. (2009), developed standards of practice and professional performance for registered dietitians (generalist, specialty and advanced) in nephrology care. Moreover, the Academy of Nutrition and Dietetics (formerly the American Dietetic Association) have established chronic kidney disease evidencebased nutrition practice guidelines; these were last updated in 2010.

The National Kidney Foundation, and the Kidney Disease Outcomes Quality Initiative, developed guidelines for clinical practice in the area of CKD. These guidelines provide clinical practice guidelines for both children, with 10 guidelines that centred on maintenance dialysis treatment, and for adults with 27 guidelines, which centred primarily on dialysis therapy. The article discussed a number of patients who need special recommendations including patients with protein-energy nutritional status and non-dialyzed patients with advanced GFR. The guidelines provide recommendations for energy and protein depending on the patient's medical and nutritional status (Kopple, 2001).

The Council of Health Services developed clinical guidelines from evidence-based fields of peritoneal dialysis management, including nutritional management. These guideline developments, based on assigned committee groups of paediatrics, children and adults, consist of senior nephrologists from various health sectors in Saudi Arabia.

\section{Nutrition and Dietetic Services and Practice in Renal Units}

A study conducted in Korea targeted 30 hospitals that have nutrition service departments to assess nutrition service and tasks of foodservice. The study summarized the results as follows:

- $28.4 \%$ of dietitians reported that 2-3 years are needed for courses about nutritional management;

- $38.6 \%$ of dietitians reported that they spend 1-2 years in the mastering of food service management; and

- $48.9 \%$ of dietitians were involved in nutrition service management; however $26.7 \%$ were involved in clinical nutrition and $26.7 \%$ involved in both. 
The thirteen components that indicate the level of performance of food service management, including food intake, menu selection, food temperature, serving mistakes and reliance on hospital food and contaminated substances, showed a low level of performance. There are five components used in enhancing nutrition service activities that showed a low performance level with a high importance score. Problem analysis showed a low performance level. According to the study undertaken by Kim et al. (2000), showed that higher performance levels were seen in hospitals under contract foodservice management with statically $(P<.0 .5)$ than hospitals under self-operated foodservice management.

Another study conducted in Saudi Arabia by Aljaaly and Khalifa (2015) about Nutrition \& Dietetics Services for Assessing Adolescents' Anthropometric status showed that three of the targeted hospitals had union adolescent medicine, four were not providing nutrition services for adolescents, and three lacked information about nutrition services. Conversely, seven dietetic departments offered nutrition services specifically for adolescents including weight problems and diabetic patients. This study found the dietitian-individualized interaction was not implemented by $70 \%$ for adolescents, $10 \%$ for paediatrics, and $20 \%$ with adults: this indicates that there are no specific guidelines to follow.

\section{Study Objectives}

The objectives of this study are:

(1) To measure current nutrition and dietetics services provided by governmental and private operating renal units in Jeddah City, and to answer the question of "What standards of nutrition and dietetics in the context of Chronic Kidney Diseases (CKD) is achieved in renal units in Jeddah City".

(2) Assess the involvement of Saudi emigrant dietitians in the renal setting.

\section{MATERIALS AND METHODS}

\section{Study Design}

This is a descriptive, cross-sectional study, evaluating nutrition and dietetic services that are delivered in the context of CKD. It covers the departments providing nutrition services to the renal units, and the involvement of emigrant Saudi dietitian alumni in renal-related services

\section{Study Setting and Area (Site)}

This is a facility based study, which involves emigrant Saudi dietitian alumni and 13 governmental and privately operated renal units in Jeddah City. These are named as follows:

- Saudi German Hospital;

- International Medical Centre (IMC) Hospital;

- Al-Jedaani Hospital;

- AlBir Center;

- Bugshan Hospital; 
- Jeddah National Hospital;

- International Dialysis Center;

- Hai Al-Jamea Hospital;

- Almustaqbal Hospital;

- Haemodialysis Center - King Abdullah Project;

- SulaimanFageeh Hospital;

- Erfan Hospital;

- King Fahad General Hospital.

\section{Study Period}

This study was conducted between February 2015 and May 2015.

\section{Study Population}

Nutrition services departments in all governmental and private sector renal units in Jeddah City, and emigrant Saudi dietitian alumni.

\section{Inclusion and Exclusion Criteria}

Inclusion criteria: departments who agreed to participate in the study from governmental and private sectors in Jeddah City.

\section{Sampling}

Convenience sampling targeting all accessible renal dialysis units in private and governmental sectors and emigrant Saudi dietitian alumni.

The final selection of renal units as study sites was based on:

- Working hours, office hours and compliance from dieticians and food service supervisors;

- Dialysis sessions, health conditions, patient companion availability for the patient.

The study sample was collected in the above-identified 13 working sites, and included 12 food service providers/departments.

\section{Study Variables}

Availability of nutrition services and dietetic care for CKD patients in targeted renal units.

\section{Data Collection}

\section{Data Collection Tool}

One set of structured face-to-face completed questionnaires for units' administrators (supervisors) (Appendix III), and electronic questionnaires to emigrant Saudi dietitian alumni. 


\section{Steps of Data Collection}

- Finalization and translation of data collection tools;

- Preparation of logistics and managers contact list needed for data collection;

- Managers of working sites were contacted and formal approval for data collection was obtained;

- Distribution of questionnaires after obtaining informed consent that explained research objectives and expected value: among nutrition services providers/departments: to assess the nutrition service scope provided to CKD patients in renal units.

\section{Data Processing and Analysis}

- The quantitative data obtained based on one set of questionnaire were coded, then sorted and entered in EXCEL spread-sheets in preparation for statistical analysis;

- Statistical analysis was conducted for the above data using Microsoft office EXCEL software 2007.

Bivariate analyses were performed to define differences in the service provided by dietitians and renal units using Chi-square analysis to detect significant relationships. Raw data (hard and soft) and analysis files will be preserved for one year after submission of results with the researchers.

\section{Ethical Considerations}

- Ethical clearance was obtained from the Ministry of Higher Education, King AbdulAziz University, Faculty of Medicine, Research Ethics Committee (REC).

\section{Limitations}

- Originally, all governmental hospitals were targeted, but due to constraints of time and the complexity of approval procedures, not all those sites were included in the study. Although sites were contacted, approval to conduct data collection was not obtained until the time of data collected;

- Non-compliance of some nutrition services supervisors and many dietitians to the applied questionnaire in the targeted facilities.

- Convenience sampling that has been used in conducting the study is not considered a gold standard sampling technique; however, it was the best choice when considering resources constraints.

\section{RESULTS}

Nutrition and Dietetic Policy, Regulation and Standards Followed by Department

Results showed that $50 \%$ of nutrition service departments were providing services for 100 and 400 beds.

All 12 departments interviewed acknowledged that they followed some legislation, regulations, standards or guidelines to practice when providing service. Figure 1 shows the 
departments identified by the type of legislation or standards they followed: these were reported as 7 (58.3\%) follow "National standards", 3 (25\%) follow "International standards", 1 (8.35\%) acknowledged following "both", and 1 (8.35\%) followed "Others". The latter department is in a private hospital that they described as Management standards.

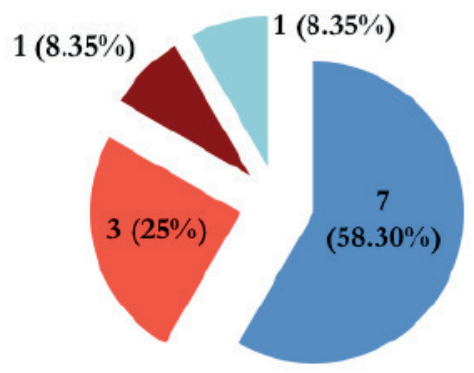

National

- International

Both

Other

Figure 1: Legislations/standards followed by nutritional departments Source: Devised by author

Departments were asked about their current accreditation status. The results represented in Table 1 showed that of the total of 12 departments, 5 (41.7\%) (all private departments) were "Not accredited at all" (either nationally or internationally), 7 (58.3\%) (including the two governmental departments and another five private departments) were "Nationally accredited", and only 3 (25\%) departments (including one governmental department and another two private departments) were "Internationally accredited". Among the list provided in the questionnaire, the following associations were named as the international accrediting bodies: ADA and two others; Hazard Analysis Critical Control Point (HACCP) and Joint Commission International $(\mathrm{JCl})$.

\begin{tabular}{|c|c|c|c|c|}
\hline \multirow[t]{2}{*}{ Facility type } & \multicolumn{2}{|c|}{ Accredited nationally } & \multicolumn{2}{|c|}{ Accredited internationally } \\
\hline & YES & NO & YES & NO \\
\hline Governmental (2) & 2 & - & 1 & 1 \\
\hline Private/Charity (10) & 5 & 5 & 2 & 7 \\
\hline TOTAL (12) & 7 & 5 & 3 & 8 \\
\hline$(100 \%)$ & (58.3\%) & (41.7\%) & (25\%) & (66.7\%) \\
\hline
\end{tabular}


Availability of Dieticians Working in the Facility

Departments were asked to identify the number of dietitians working in the facility. As shown in Figure 2, 4 (33.35\%) departments had only "one dietician", 2 (16.65\%) had "two dieticians", 2 $(16.65 \%)$ had "three dieticians", and $4(33.35 \%)$ claimed they had "more than three dieticians.

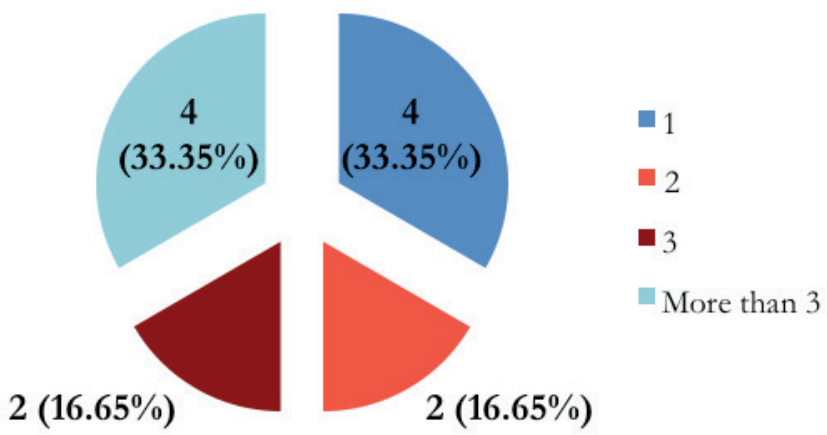

Figure 2: Number of dietitians working in the facility

Source: Devised by author

Medical Team Involved in Patients' Management in Renal Unit

Departments were asked to identify, once again to their knowledge, the team members involved in managing patients in the renal unit. Table 2 summarizes the departments' responses: of the total of 12 departments, 9 (75\%) named "dietitians" as a team member involved in managing patients in the renal unit, leaving $3(25 \%)$ departments that felt their dietitians were not considered as members of the renal unit medical team.

\section{Table 2: Medical Team Involved in Patients' Management in Renal Unit}

\begin{tabular}{lll} 
Team Member & Departments acknowledging them as part of the team \\
\hline & Number & Percentage \\
\hline Doctor & 10 & $83.3 \%$ \\
Renal coordinator & 0 & 0 \\
Dietitian & 9 & $75 \%$ \\
Medical social worker & 5 & $41.7 \%$ \\
Nephrologist & 2 & $16.7 \%$ \\
Pharmacist & 3 & $25 \%$ \\
\hline Source: Devised by author & &
\end{tabular}




\section{Emigrant Saudi Dietitians who were Involved in Renal Related Services}

None of the emigrant Saudi dietitians who participated in this study $(n=38)$ were involved with renal-related services.

\section{DISCUSSION, CONCLUSIONS AND RECOMMENDATIONS}

\section{Discussion}

The overall objectives of the study were to assess the standards of nutrition and dietetics services delivered to Chronic Kidney Diseases (CKD) patients in renal units of Jeddah City, as well as assessing the involvement of Saudi emigrant dietitians in a renal setting. A statistical and diagrammatic analysis on questionnaires distributed among managers of nutrition services and Saudi emigrant dietitians who were available were conducted.

Results showed that $50 \%$ of nutrition service departments provided services for 100 and 400 beds; this indicates the importance of increasing the number of dietitians working in renal units. About 33\% of the departments reported having only one dietitian working in the unit. Another study in Jeddah showed that one dietitian was available for every 40 patients (Aljaaly and Khalifa, 2015).

Although a dietitian is an one of the important members of the medical team in renal units (Ikizler et al., 2014), 25\% of departments thought their dieticians were not considered as an important member of the renal medical team. Moreover, $16.7 \%$ of departments give the responsibility to nurses or nutritionist in managing renal patients.

Considering a variety of special diets and restrictions, many have offered the patients a daily menu to choose from. However, some diets based on religion were not offered by these departments, which had a conflict with the professional obligations of patients with other religions (Office PPA, 2009). This could be due to the lower number of patients with religions other than Islam who are provided services in these units.

Religious Rights and the Importance of Spiritual Care During Treatment 2009 [cited 2015 May 4].

Of the total number of departments, $25 \%$ followed international standards in managing CKD patients, compared to $58.3 \%$ who were following national standards. Another study that was conducted to assess anthropometric services in Jeddah hospitals found that $10 \%$ of nutrition service departments followed national based guidelines (Aljaaly and Khalifa, 2015).

\section{Conclusions}

In conclusion, it is important that nutritional therapy be applied to CKD patients to improve goals and outcomes of medical management. Dietitians must work with standards to satisfy patients. Nutrition services must be aware of all information of dietitians working in the facility in order to have beneficial results.

Dietetics is an evidence-based profession with research and outcome evaluation at its base. Based on the results of the present study, there is a need to have information about dietetics services in SA to be readily available and accessible through the Internet, as little data have been published on the services and work of dietitians who are taking care of CKD patients in the country. 


\section{Recommendations}

This study calls for a critical call for professionals in the field of nutrition and dietetics, to assemble a group of leaders and thinkers, particularly dietitians, dietetic educators and researchers to help in the development of professionalism in the area, and to unify dietetic services in Saudi Arabia.

We recommend conducting further studies in different areas related to the dietetic services other than renal units.

- Further research and future trends as follows:

- In order to enhance patients' outcome:

- Further studies are needed to compare between dietetic policies and actual practice among health care facilities in Jeddah City and other parts of SA;

- Provide advanced techniques that support more nutrition education services, based on patients' need within health care facilities; these need to be applied in renal units;

- Undertake routine supervision and periodic evaluation of dietetic and nutrition services provided in renal units.

- Develop policies to standardize nutrition services and inform decision makers at the Saudi Dietetic Association (SDA) or Saudi commission for health specialists (SCFHS) provided to patients, in health care facilities in different cities of Saudi Arabia;

- Undertake cost effectiveness and cost benefits analyses of the implemented interventions, based on national and international standardized policies;

- Emphasize the role of the dietitian in the renal care team;

- Practice under the umbrella of national organization bodies such as the Saudi Dietetic Association;

- Cover the shortage of dietitian employment as evidenced by nutrition care provided by health care workers other than dietitians, ex: nurses.

\section{REFERENCES}

Activities of the World Kidney Day Launched under the Theme: "Kidney Health for All" 2015 [updated 17 March 2015; cited 23 April 2015]. Available from: http://www.moh.gov.sa/en/Ministry/MediaCenter/News/Pages/ News-2015-03-15-002.aspx.

Aljaaly, E. and Khalifa, N. (2015): Nutrition and Dietetics Services for Assessing Adolescents' Anthropometric status in Saudi Arabia. Journal of Scientific Research, 7(4), pp.2277-8179.

Al-Sayyari, A.A. and Shaheen, F.A. (2011): End stage chronic kidney disease in Saudi Arabia. A rapidly changing scene. Saudi Medical Journal, 32(4), pp.339-46.

Alsuwaida, A.O., Farag, Y., Al Sayyari, A.A., Mousa, D., Alhejaili, F., Al-Harbi, A., Housawi, A., Mittal, B.V. and Singh, A.K. (2010): Epidemiology of chronic kidney disease in the Kingdom of Saudi Arabia (SEEK-Saudi investigators) - a pilot study. Saudi Journal of Kidney Diseases and Transplantation. 21(6), pp.1066-1072.

Ash, S., Campbell, K., MacLaughlin, H., McCoy, E., Chan, M., Anderson, K., Corke, K., Dumont, R., Lloyd, L., Meade, A., Montgomery-Johnson, R., Tasker, T., Thrift, P. and Trotter, B. (2006): Evidence based practice guidelines for the nutritional management of chronic kidney disease. Nutrition \& Dietetics, 63, pp.S33-S45.

Brommage, D., Karalis, M., Martin, C., McCarthy, M., Benner, D., Goeddeke-Merickel, C.M., Wiesen, K., Byham-Gray, L. and Lang House, J. (2009): American Dietetic Association and the National Kidney Foundation Standards of Practice and Standards of Professional Performance for registered dietitians (generalist, specialty, and advanced) in nephrology care. Journal of the American Dietetic Association, 109(9), pp.1617-25. e33.

Escott-Stump, S. (2008): Nutrition and diagnosis-related care. Lippincott Williams \& Wilkins. 
Idris, S.M. and Al Jannakl, N. (2013): The Role of Dietitian in Nutrition Service at King Khalid Hospital: Case Study. International Journal of Science and Research, India Online ISSN: pp.2319-7064.

Ikizler, T.A., Franch, H.A., Kalantar-Zadeh, K., ter Wee, P.M. and Wanner, C. (2014): Time to Revisit the Role of Renal Dietitian in the Dialysis Unit. Journal of Renal Nutrition, 24(1), pp.58-60.

Jha, V., Garcia-Garcia, G., Iseki, K., Li, Z., Naicker, S., Plattner, B., Saran, R., Wang, A.Y.-M. and Yang, C.-W. (2013): Chronic kidney disease: global dimension and perspectives. The Lancet, 382(9888), pp.260-72.Kim, H.J., Jang, E.J. and Hong, W.S. (2000): Task analysis on foodservice, clinical nutrition service in hospital dietetic departments. Journal of the Korean Dietetic Association, 6(2), pp.148-60.

Kopple, J.D. (2001): National kidney foundation K/DOQI clinical practice guidelines for nutrition in chronic renal failure. American Journal of Kidney Diseases, 37(1), pp.S66-S70.

life Mkmpm. Partnering Your Healthcare Team 2015 [cited 2015 May 17]. Available from: http://www. mykidneyplan.com/My-Kidney-Plan-Partner-with-Healthcare-Team.

National Guideline C. Chronic kidney disease evidence-based nutrition practice guideline. 2010

Office PPA. Religious Rights and the Importance of Spiritual Care During Treatment 2009 [cited 2015 May 4]. Available from: https://www.sse.gov.on.ca/mohltc/ppao/fr/Pages/InfoGuides/1Advocacy_F. aspx?openMenu=smenu_1Adv

Van Wamelen, C. (1980): The role of the dietician as a member of the medical team. South African medical journal (Suid-Afrikaanse tydskrif vir geneeskunde), 57(26), pp.1089-91.

\section{BIOGRAPHICAL NOTES}

Nahlaa A. Khalifa is a Sudanese national. She is an Assistant Professor at the Clinical Nutrition Department, Faculty of Applied Medical Sciences, King Abdulaziz University in Jeddah, Saudi Arabia. She holds a PhD in food science and nutrition from Khartoum University in cooperation with Hanover University in Germany. She is the Coordinator of the evaluation and quality assurance programme, Chairperson of the Academic Advising Committee, Member of the Strategic Plan Committee, Coordinator of undergraduate curriculum development, revision and accreditation programme, and a Thinkbuzan Licensed Instructor (TLI) and TOT. She has been awarded certificates for the preparation, participation and attendance for health, community and educational missions. She has been an invited speaker at many conferences and has published articles on food science and nutrition. Her main interests are in alternative medicine, nutrigenomic and medical nutrition therapy. Her interests also lie in the activation of modern information technology applications in teaching and research for outstanding teaching methods and curriculum development and accreditation. 